\title{
Pandemia, distopia e sociedade de controle
}

\author{
Pandemic, dystopia and control society
}

\section{Rodrigo Barbosa Lopes*}

Resumo: Abordamos neste artigo o problema da pandemia desde um ponto de vista filosófico. Para tanto, com base em autores como Michel Foucault, Gilles Deleuze e Gregory Claeys, procuramos analisar a relevância do tema da pandemia para uma sociedade de controle à luz de noções como distopia, problematização e governamentalidade.

Palavras-chave: Governamentalidade; Distopia; Filosofia; Pandemia; Problematização

Abstract: In this article we approach the pandemic problem from a philosophical point of view. Therefore, based on authors such as Michel Foucault, Gilles Deleuze and Gregory Claeys, we seek to analyze the relevance of the pandemic theme for a control society in the light of notions such as dystopia, problematization and governmentality.

Keywords: Governmentality; Dystopia; Philosophy; Pandemic; Problematization

\section{Notas introdutórias}

Abordar o tema "Pandemia e Filosofia" é um desafio que, por razões diversas, só poderá ser superado a muitas mãos, em muitas frentes de trabalho, que não exclusivamente filosóficas. A despeito da pujança da filosofia, atestada por muitas situações em que filósofos responderam a desafios no decurso da história, fazer frente à pandemia - contê-la, já que não se trata mais de evitá-la -, é uma tarefa que advoga o concurso de muitas outras frentes de trabalho: da medicina; da estatística; das políticas públicas de saúde, nacionais e internacionais; em quaisquer casos, de medidas sanitárias contundentes e eficazes, como a quarentena, o contingenciamento social horizontal, etc. De sorte que é no mínimo razoável supor que estamos diante de uma tarefa multifatorial, multirreferecial e multidisciplinar. Por isso é tão difícil executá-la com a urgência que é exigida para abarcar o problema, mas a busca de alternativas para uma solução pode encontrar no saber filosófico algumas pistas.

Contudo, não é apenas a urgência que está colocada em questão, mas sobretudo o porvir: que futuro nos prepara a fase pós-pandemia? Por suposto, não é o bastante dizer que as pessoas serão diferentes, a sociedade será diferente, a economia será diferente. A bem da verdade, nem tudo é destino ou consequência. Felizmente. E é aqui que a filosofia desempenha um papel especial, pois, como argumentava Foucault, à diferença de uma longa tradição que fez do universal e da verdade objetos do pensamento, Nietzsche introduziu o hoje, o presente, no campo da filosofia ${ }^{1}$. Reconhecemos em Foucault, portanto, a referência ao trabalho da filosofia como uma forma de jornalismo, um jornalismo filosófico que investiga os eventos atuais. Consoante a essa hipótese, é tarefa da filosofia fazer um diagnóstico da atualidade: sobre o presente, mas com o propósito de elaborar o futuro.

Desse modo, discorrer sobre a pandemia é uma tarefa que pode trilhar a via do pensamento filosófico, o que propomos fazer aqui, apesar das limitações impostas pelo tema e de espaço. Na verdade, como em tese é uma tarefa que poderia receber o concurso de muitos

${ }^{1}$ FOUCAULT, Dits et écrits II, 434. Dits et écrits III, 431; 573. 
filósofos e vertentes de pensamento, a primeira dificuldade que se impõe é da ordem da seleção, da escolha ou da preferência. De qualquer modo, independentemente da via escolhida, a reflexão terminará em outra trilha, em outras vias de abordagem para as quais o pensamento filosófico não deixa de despertar um sentimento de espanto ou de contestação. 0 que queremos dizer é que falar filosoficamente pode até despertar a suspeita sobre se os resultados ajudarão a abarcar a pandemia, mas isso não é mais incerto que os combates travados em outras frentes de ação obtenham um sucesso duradouro. A despeito disso, indicaremos a análise do contexto de pandemia pela via filosófica da problematização, pondo em tela algumas nuances estéticas - considerações sobre a literatura distópica - e políticas sobre o governo da vida. Propomos um modo de fazê-la em três movimentos combinados, a saber:

$1^{\mathrm{O}}$ - Da narrativa distópica à pandemia como realidade;

$2^{2}$ - 0 diagnóstico da atualidade como modo de problematização; e

3ㅇ - 0 problema da governamentalidade em uma sociedade de controle.

\section{Quando a distopia se torna realidade ${ }^{2}$}

Em Le souci de la vérité, o tratamento que Foucault imprimiu aos temas por ele analisados nesta entrevista à Magazine littéraire, em maio de 1984, nos faz lembrar, oportunamente, que "sempre se chega ao essencial retrocedendo"3. Para abordarmos, pois, em parte a grave crise de saúde que nos assola atualmente, voltemos um pouco no tempo para recordar o pronunciamento de Tedros Adhanom Ghebreyesus, diretor geral da Organização Mundial da Saúde (OMS):

Nas últimas duas semanas, o número de casos de COVID-19 fora da China aumentou 13 vezes e o número de países afetados triplicou. Atualmente, existem mais de 118.000 casos em 114 países e 4.291 pessoas perderam a vida. Milhares estão lutando por suas vidas nos hospitais. Nos próximos dias e semanas, esperamos ver o número de casos, o número de mortes e o número de países afetados aumentarem ainda mais. A OMS está avaliando esse surto o tempo todo e estamos profundamente preocupados com os níveis alarmantes de disseminação e severidade e com os níveis alarmantes de inação. Portanto, avaliamos que a COVID-19 pode ser caracterizada como uma pandemia ${ }^{4}$.

Era 11 de março de 2020, data que marcou, não o advento, mas a confirmação pela OMS de que o mundo assistia, sob grande consternação, ao surto de um novo coronavírus e à consequente pandemia de Covid-19. Não era mais necessário esperar por outras evidências que confirmassem o que a imprensa internacional noticiava: a pandemia havia se instalado mundo afora; somavam-se já 114 países afetados, mais de quatro mil mortes causadas pela doença, outras tantas viriam. Era preciso então agir. Ao passo que assistíamos o número de infectados aumentar dia após dia, vimos o discurso oficial mudar radicalmente, da prudência das declarações à urgência das medidas sanitárias. Apenas dois dias após a declaração do diretor geral Tedros Adhanom, assistimos a OMS noticiar a criação de um Fundo de Resposta Solidária (Solidarity Response Fund) à pandemia de Covid-19, doença causada pelo

\footnotetext{
2 Para a elaboração deste artigo, fizemos uso de algumas bibliografias cuja referência para a consulta foram as edições publicadas no idioma original, em inglês ou em francês. Portanto, para as citações diretas empregamos a expressão "tradução nossa". Como se verá ao final das referências bibliográficas, indicamos algumas edições traduzidas para o português.

3 FOUCAULT, Dits et écrits IV, 669 (tradução nossa).

4 Discurso de abertura do diretor geral da OMS no briefing da mídia sobre a Covid-19. Disponível em: https://www.who.int/dg/speeches/detail/who-director-general-s-opening-remarks-at-the-media-briefing-oncovid-19---11-march-2020. Acesso em: 20 abr. 2020 (tradução nossa).
} 
coronavírus SARS-CoV-2. Com este fundo, espera-se arrecadar recursos financeiros de uma ampla gama de doadores para reforçar o trabalho de apoio aos países no enfrentamento da doença. Não é demais lembrar que este é o primeiro fundo do gênero no mundo, criado pela United Nations Foundation e Swiss Philanthropy Foundation em colaboração com a Organização Mundial da Saúde, o qual tem permitido que tanto indivíduos quanto empresas e instituições contribuam diretamente para somar esforços no combate global à pandemia. De lá para cá, confirmou-se o que infelizmente era esperado: um crescimento exponencial de casos de infectados e de óbitos, e ainda não vislumbramos o fim, que permanece incerto ${ }^{5}$. As perdas são irreparáveis!

Esta situação dramática não é uma visão exagerada dos fatos, nem ficcional. Aliás, talvez seja oportuno considerar que, sendo verdade que a arte imita a vida, o inverso também seja possível. É claro que falamos figurativamente, mas vamos analisar a questão. No mês anterior à confirmação do novo agente do coronavírus em 31 de dezembro de 2019, a gigante da produção de streaming, Netflix, fez uma aposta no assunto "A próxima pandemia", levandoo ao ar em 7 de novembro com um episódio homônimo na segunda temporada da série documental "Explicando". Neste episódio, com apenas 20 minutos de duração, assiste-se o desenrolar de situações variadas combinando pandemias do passado com novas estimativas; alterações climáticas drásticas; previsões alarmantes de especialistas. Logo no primeiro minuto, um convite à reflexão: "Imaginemos por um segundo todas as formas de que o mundo poderia acabar, mas tem uma coisa que com toda a certeza está entre as coisas mais prováveis de acabar com o mundo: a pandemia é o nosso maior risco. Sabemos disso porque já vimos isso antes, algumas vezes". E, a despeito dos avanços tecnológicos e das melhorias nos sistemas de vigilância e comunicação; de treinamentos e respostas de trabalho melhoradas; de diagnósticos avançados e vacinas terapêuticas; de organizações internacionais como a OMS, ainda assim, "o risco de acontecer isso de novo nunca foi tão grande". Na verdade, todo o documentário aponta para um cenário no qual o otimismo dá lugar ao pessimismo e à não utopia. E, então...

Fazemos esta alusão em virtude da similaridade com o tema abordado, que não foi o primeiro e provavelmente não será o último a tratar desse tipo muito especial de assunto: a literatura distópica. Reconhecido internacionalmente pelos seus trabalhos, Gregory Claeys em Dystopia: a natural history argumentou que: "A literatura distópica emergiu como uma das correntes intelectuais mais poderosas do nosso tempo. Como os seus insights podem variar, complementar ou ficar aquém da história que examinamos até agora, devemos considerá-la"6. 0 que ela tem de tão especial? Para dizer sucintamente, muitas coisas. A começar por uma operação de técnica literária com a qual o escritor, inventor por excelência de realidades como de memórias, empresta às narrativas, mesmo as mais improváveis, um senso de justeza ou de verossimilhança. Foi Mark Twain quem não nos deixou esquecer que a verdade é mais estranha que a ficção, já que esta precisa fazer sentido para ser crível, ao passo que aquela, não; e Manoel de Barros, poeta da incompletude, que nos confundia afavelmente ao afirmar que noventa por cento do que escrevia era invenção, só dez por cento era mentira. A história tem seus muitos exemplos. Usualmente, conceberíamos a distopia afeita à literatura, como o romance, ou em obras cinematográficas, mas "há usos empíricos e não literários do termo"7, esclarece Claeys. Estaríamos, talvez, diante de experiências que encarnam, no pretérito imperfeito, as distopias do tempo presente? - "Ainda ontem assistíamos consternados a

\footnotetext{
$5 \mathrm{Na}$ data do discurso de abertura do diretor geral sobre a pandemia da Covid-19, de acordo com dados da própria OMS - disponíveis em https://covid19.who.int/ - eram 4.583 óbitos da doença confirmados no mundo. No cumulativo, em de 10 de abril de 2020 foram registradas 92.940 mortes (deaths over time), um crescimento de 2.027,93\% em 30 dias de pandemia, ou o equivalente a quase 20,28 vezes o número de casos registrados em 11 de março. E os indicadores continuam a aumentar assustadoramente. Em 25 de abril, data de conclusão deste artigo, já se somavam 2.724.809 casos confirmados e 187.847 mortes.

${ }^{6}$ CLAEYS, Dystopia: a natural history, 268 (tradução nossa).

${ }^{7}$ CLAEYS, Dystopia: a natural history, 5 (tradução nossa).
} 
possibilidade de surgimento de uma nova pandemia. E vejam agora o que está acontecendo!" - alguém em algum lugar do mundo está supondo isso agora, de sorte que uma referência direta ao episódio comentado e à pandemia atual é inevitável. Então, a resposta é sim. Tudo se passa como se a realidade não falasse apenas por si só.

Realidade ou distopia? Não é tão simples assim. Obras clássicas de literatura do século XX, como Admirável mundo novo (1931), de Aldous Huxley, 1984 (1949), de George Orwell, Fahrenheit 451 (1953), de Ray Bradbury, ou Laranja Mecânica (1962), de Anthony Burgess, retratam exemplarmente, ressalvadas as suas diferenças, as distopias daqueles tempos, ora projetando-as no futuro ora antecipando-as no presente, mas todas elas enredadas pelas incertezas que espreitavam a sociedade. Podemos até supor que tinham um valor de aprendizado, apontando para o que o mundo e as pessoas se tornariam caso não mudassem a direção dos acontecimentos, o rumo das coisas. Neste grupo seleto poderiam ser incluídas ainda a literatura fantástica, o realismo mágico e até a ficção científica, mas não é o caso aqui. Poderíamos engrossar esta fileira incluindo outras tantas narrativas cotidianas, orais ou escritas, que não se limitaram ao rigor literário das obras e que, por assim dizer, sucumbiram ao desejo de se tornar realidade; ou talvez não. Talvez tenham emprestado à realidade as técnicas literárias indispensáveis para torná-la distópica. A sociedade atual tem muito de parecido com uma utopia negativa. Paradoxo? E não seria este o caso? Ora, assistimos como testemunhas a multiplicação das características que a definem: vigilância tecnológica; rastreamento virtual de indivíduos pelo celular; temor e intolerância exacerbados; violência banalizada e ódio generalizado; totalitarismo morais e religiosos; autoritarismos disfarçadamente democráticos; apatia social e negação da realidade; privação de alimentos e remédios em muitos lugares do mundo; determinismos estatísticos e algorítmicos; descontrole climático e catástrofes ambientais, entre outras. Distopias é o que não eram mais, ou era precisamente isso o que deixavam de ser. São tão reais quanto a pandemia que vivemos. Isso significa, provavelmente, que a narrativa distópica deixou de ser uma abordagem alternativa da sociedade - não utópica, é importante lembrar - para se tornar uma leitura do presente transportada para realidades não tão distantes assim. Não é o futuro próximo ou imediato que está em questão, mas o presente, a atualidade.

Voltemos ao episódio "A próxima pandemia". No ponto de interrogarmos se estaríamos falando de eventos ou imersos em uma experiência ficcional que beira a realidade, não se trata de considerar que o documentário preanunciou com muita assertividade a pandemia de Covid-19, como o seu sucedâneo, menos ainda que os comentários lá apresentados tinham o condão de profetizar ou de anunciar dramaticamente os dias futuros. $\mathrm{Na}$ melhor das hipóteses, acompanhamos bastante interessados a produção audiovisual de uma narrativa dis-tópica tomada no sentido literal do termo - "A palavra [distopia] é derivada de duas palavras gregas, dus e topos, significando um lugar doente, ruim, defeituoso ou desfavorável"8 -, mas que agora se faz valer não em virtude da criação literária ou da produção cinematográfica, mas por força de fatos que não podemos negar. É como se a distopia tivesse finalmente superado a utopia: ela se tornou real na medida em que a facticidade dos acontecimentos a tornou possível. Podemos talvez tergiversar e alegar que uma coisa não está ligada a outra, ou que daquela expectativa chegamos ao atual estado de coisas. Na verdade, não importa muito determinar se alguns estavam certos antes, ou se tudo não passou de uma coincidência. Nada disso é relevante. Mas o que é relevante é considerar, desde um ponto de inflexão do pensamento no tempo, os fatores que levaram a situação de pandemia da distopia à realidade. Qual o ponto? Supondo que Foucault estivesse certo ao afirmar que se chega ao essencial retrocedendo, então seria razoável presumir que o ponto de inflexão diz respeito à natureza das tomadas de decisão políticas, como aquela proferida pela OMS sobre a declaração do estado de pandemia, e que fez repercutir nos estados nacionais, os quais

${ }^{8}$ CLAEYS, Dystopia: a natural history, 4 (tradução nossa). 
fizeram ressoar em suas populações, as medidas sanitárias cabíveis - umas mais severas, outras nem tanto -, mas que representam com um elevado grau de verossimilhança aquilo que Foucault analisou muito bem sob o título de biopolítica.

Em Naissance de la biopolitique, organizado para o Annuaire du Collège de France, vemos Foucault esclarecer a respeito da biopolítica:

[...] Eu quis dizer com isso a maneira pela qual, a partir do século XVIII, tentou-se racionalizar os problemas colocados para a prática governamental pelos fenômenos próprios de um conjunto de viventes constituídos em população: saúde, higiene, natalidade, longevidade, raça... Sabe-se quanto espaço esses problemas ocuparam desde o século XIX, e quais questões políticas e econômicas eles colocaram até hoje9 .

0 essencial que identificamos ao analisar fatos no tempo e ponderar como observadores treinados sobre a crise que coloca em risco centenas de milhares de grupos de indivíduos é que o governo da vida, e tudo o que dele decorre, é um tipo de política forjada precisamente para gerir acontecimentos que sobrevêm às populações: a natalidade, a economia, a saúde; o controle de pandemias, por exemplo. Nada obstante, tudo isso é visto com muita desconfiança, porque se a ideia de uma biopolítica é aumentar o gradiente de manutenção da vida e de outras práticas sociais, como as instituições e a própria política, isso não ocorre sem o uso de técnicas de controle cada vez mais generalizadas e de dispositivos de disciplina, como a vigilância; embora, tal como argumentava Deleuze, "sociedades disciplinares é o que já não éramos mais, o que deixávamos de ser"10. As transformações sociais que testemunhamos, decorrentes de causas endógenas ou naturais, como a pandemia, não são sentidas sem que uma transformação igualmente profunda aconteça na ordem do pensamento e das ideias.

\section{Diagnosticar a realidade, tarefa da filosofia}

Comentávamos no início que Foucault entendia o trabalho da filosofia como uma forma de jornalismo que investiga os eventos atuais, sobretudo a respeito de Nietzsche. É o que podemos depreender, por exemplo, do texto Le monde est um grand asile, que veio a público em junho de 1973:

Eu me considero um jornalista, na medida em que o que me interessa é a atualidade, o que se passa ao nosso redor, o que nós somos, o que acontece no mundo. A filosofia, até Nietzsche, tinha por razão de ser a eternidade. 0 primeiro filósofo jornalista foi Nietzsche. Ele introduziu o hoje no campo da filosofia. Antes, o filósofo conhecia o tempo e a eternidade. Mas Nietzsche tinha obsessão pela atualidade. Eu penso que o futuro, somos nós que o fazemos. O futuro é a maneira com a qual reagimos ao que se passa, é a maneira pela qual transformamos em verdade um movimento, uma dúvida. Se queremos ser mestres de nosso futuro, nós devemos colocar fundamentalmente a questão do hoje. Isso porque, para mim, a filosofia é uma espécie de jornalismo radical ${ }^{11}$.

Esta forma de interrogação crítica é apresentada assertivamente por Foucault como uma herança nietzscheana. Pois que em face da longa tradição que havia feito da verdade, da essência e do universal objetos da Filosofia, Nietzsche teria introduzido no campo da história

\footnotetext{
${ }^{9}$ FOUCAULT, Dits et écrits III, 818 (tradução nossa).

${ }^{10}$ DELEUZE, Conversações, 220.

${ }^{11}$ FOUCAULT, Dits et écrits II, 434 (tradução nossa).
} 
das ideias, e para todos os efeitos, a diferença e a singularidade. Isto é, a irrupção no presente de relações de forças que introduziram, no campo do pensamento, o valor, a vontade e o sentido.

Isso nos leva a crer que Foucault tenha sido, entre os filósofos de sua geração, aquele que melhor compreendeu que a tarefa da filosofia deveria assumir as feições de um trabalho crítico do pensamento como diagnóstico da atualidade, o que ele chamou de "ontologia do presente"12 ou "ontologia crítica de nós mesmos"13. Além dessas duas expressões, ele utilizou também "ontologia da atualidade"14, e é quanto a esta última indicação que o vemos afirmar: "a filosofia como problematização de uma atualidade e como interrogação pelo filósofo desta atualidade da qual ele faz parte e com relação à qual ele tem que se situar"15.

Portanto, era presumível concluir, depois de feita uma referência remissória às suas publicações, que a noção que unificava todos os estudos por ele realizados desde Histoire de la folie é a "problématisation", embora ele não a tivesse isolado suficientemente, tal como viria a fazer, depois, nos trabalhos da década de 1980. Le souci de la vérité é um caso exemplar disso:

Problematização não quer dizer representação de um objeto preexistente, nem tampouco a criação pelo discurso de um objeto que não existe. É o conjunto das práticas discursivas ou não discursivas que faz alguma coisa entrar no jogo do verdadeiro e do falso e o constitui como objeto para o pensamento (seja sob a forma da reflexão moral, do conhecimento científico, da análise política etc.) ${ }^{16}$.

Outros trabalhos, destacadamente What is Enlightenment?17 e Polémique, politique et problématisations ${ }^{18}$, ambos datados de 1984, atestam que a atividade filosófica como o estudo dos modos de problematização norteara as escolhas e a conduta de Foucault em face dos desafios supervenientes de seu problema geral de pesquisa. Por força deste esclarecimento, se o trabalho do filósofo se voltava, pois, ao problema das relações entre o sujeito, a verdade e a constituição da experiência - como fica evidente em Une esthétique de l'existence ${ }^{19}$-, tanto mais importa destacar a questão do sujeito e as práticas históricas de constituição da subjetividade como problema central de sua filosofia. Sobretudo nos dois últimos anos de sua vida, vimo-lo esclarecer que o trabalho filosófico tinha a ver precisamente com isso: "O estudo dos (modos de) problematizações (isto é, do que não é constante antropológica nem variação cronológica) é, portanto, a maneira de analisar, em sua forma historicamente singular, as questões de alcance geral"20.

Consoante a essa argumentação, a questão que é urgente analisar não é aquela em que uma determinada situação histórica, ou em relação a algo que experimentamos como contemporâneo, delinearia a razão e a justificativa para uma reflexão filosófica. Não se trata, inclusive, de encontrar ou reconhecer na situação histórica atual a razão para a tomada de uma decisão filosófica (esta era a ressalva que fazíamos no início quanto ao desafio de abordar a pandemia desde um ponto de vista filosófico). A questão tem outra importância e, igualmente, uma natureza diferente.

A questão tem por objeto o que é este presente, ela tem por objeto inicialmente a determinação de certo elemento do presente que se trata de

\footnotetext{
12 FOUCAULT, Dits et écrits IV, 687 (tradução nossa).

${ }^{13}$ FOUCAULT, Dits et écrits $I V, 577$ (tradução nossa).

14 FOUCAULT, Dits et écrits IV, 688 (tradução nossa).

15 FOUCAULT, Dits et écrits IV, 680-681 (tradução nossa).

${ }^{16}$ FOUCAULT, Dits et écrits $I V, 670$ (tradução nossa).

17 FOUCAULT, Dits et écrits IV, 562-578.

18 FOUCAULT, Dits et écrits IV, 591-598.

19 FOUCAULT, Dits et écrits IV, 731.

${ }^{20}$ FOUCAULT, Dits et écrits IV, 577 (tradução nossa).
} 
reconhecer, de distinguir, de decifrar entre todos os outros. 0 que é que, no presente, faz sentido atualmente para uma reflexão filosófica?21.

A respeito da pandemia, a questão que pomos em evidência não são os problemas sanitários imediatos, e por essa razão, também, outros de ordem econômica, todos muito graves; mas um problema que é intrínseco à racionalidade dos estados e aos governos: a política. De maneira que diagnosticar a atualidade tem a ver com essa atividade de determinar o elemento do presente que se deve reconhecer, separar e decifrar entre todos os outros. 0 que no presente faz sentido para uma reflexão filosófica? Para o caso em questão, são as implicações para a política dos problemas decorrentes da pandemia. A premissa da qual partimos, portanto, é consoante o argumento de Foucault: "É verdade que minha atitude não decorre dessa forma de crítica que, a pretexto de um exame metódico, recusaria todas as soluções possíveis, exceto uma, que seria a boa. Ela é de preferência da ordem da 'problematização': ou seja, da elaboração de um domínio de fatos, práticas e pensamentos que me parecem colocar problemas para a política"22.

Contudo, mapear entre os problemas da pandemia as razões para questionar a política é, primeiro que tudo, examinar as relações que experiências desse tipo acarretam para a investigação de temas relevantes, destacadamente a governamentalidade. Mas isso não pode significar, como nos lembra Foucault, "que se buscará na política o princípio constituinte dessas experiências ou a solução que regulará definitivamente seu destino"23. É preciso elaborar os problemas que experiências desse tipo colocam para a política, eles não são dados de pronto ao conhecimento.

\section{Governamentalidade e sociedade de controle}

Tomemos como exemplo a análise que fizeram Pierre Dardot e Christian Laval com uma matéria sobre o tema "A prova política da pandemia", encontrada no Dossiê Coronavírus e Sociedade da Boitempo Editorial:

A pandemia da Covid-19 é uma crise global, sanitária, econômica e social excepcional. Poucos acontecimentos históricos podem ser comparados a ela, pelo menos na escala das últimas décadas. Esta tragédia se afigura, agora, como um teste para toda a humanidade. Trata-se de uma provação no duplo sentido da palavra: dor, risco e perigo, por um lado; teste, avaliação e julgamento, por outro. 0 que a pandemia está testando é a capacidade das organizações políticas e econômicas de lidar com um problema global vinculado à interdependência dos indivíduos, ou seja, algo que afeta a vida social de todos de uma forma básica. Como uma distopia que se torna realidade, o que estamos experimentando agora revela aquilo que, com as mudanças climáticas em curso, aguarda a humanidade em poucas décadas se a estrutura econômica e política do mundo não mudar muito rápida e radicalmente ${ }^{24}$.

Está aqui um exemplo de problematização, o qual aponta para os desafios que circundam a prática das organizações políticas e econômicas de responderem com senso de urgência e efetividade aos problemas que superabundam em tempos de pandemia: sanitários, econômicos, sociais... Temos assistido, senão uma falência aguda, ao menos uma crise profunda das instituições que antes deveriam salvar vidas; os hospitais, por exemplo. Isso

\footnotetext{
${ }^{21}$ FOUCAULT, Dits et écrits $I V, 680$ (tradução nossa).

22 FOUCAULT, Dits et écrits $I V, 593$ (tradução nossa).

${ }^{23}$ FOUCAULT, Dits et écrits IV, 594 (tradução nossa).

${ }^{24}$ DARDOT; LAVAL, A prova política da pandemia, 1.
} 
atesta, de certo modo, que a racionalidade e as estratégias biopolíticas de governo não garantem a contento o bem-estar social e a promoção da saúde, seja em qual escala for. Basta lembrar os problemas crônicos que afetam o sistema de saúde do Brasil: a pandemia não os criou, mas os agravou seriamente. Não podemos ignorar que alguns países estão mais bem preparados no enfrentamento da pandemia que outros, contudo isso destoa da situação precária que afeta a maioria dos países pobres no mundo.

Pois bem, a problematização, que abarcou em grande parte a interrogação crítica da atualidade, conforme Foucault, indica um tipo de análise filosófica devotada à elaboração de um domínio de acontecimentos, discursos e práticas que consiste precisamente nisso: elaborar os problemas que informam uma dada realidade, constitui-los na relação com os saberes específicos que procuram explicá-la, ou com as nuances estéticas ${ }^{25}$ e as implicações políticas do governo da vida em meio à pandemia. Falamos, portanto, da problematização para colocar em destaque o problema que afeta a coerência da prática discursiva biopolítica atual, qual seja: a governamentalidade estatística (a face menos filosófica da biopolítica, talvez).

É patente, portanto, que a questão não é a política pensada na generalidade, mas um tipo especial de governo da vida, o qual, apesar de toda a racionalidade estatística e das técnicas de controle, age com sofreguidão no afã de responder à crise humanitária desencadeada pela pandemia. Sentimos como se estivéssemos sempre um passo atrás. E, na ausência de uma solução definitiva - como seria, em tese, a vacina - emprega-se ao menos as soluções concretas diante da já retesada gama de alternativas disponíveis, como a quarentena e o isolamento social. São práticas efetivas, por certo, mas não são definitivas. E talvez, por essa razão, o sentido de "paliativo" nunca foi tão urgente como agora, ao menos recentemente. É muito provável que a política como a conhecemos vá sobreviver a tudo isso, mas receamos que centenas de milhares de vidas humanas, não.

Resulta disso que o problema não recai sobre os indivíduos tomados isoladamente, contudo, também, não é em relação ao seu conjunto que o vemos sobrestar. 0 que a governamentalidade preside, de acordo com certas regularidades e normas, são as populações e os fenômenos que delas advêm, e é isso o que tem feito os estados nacionais e as organizações internacionais, como a OMS. Tudo isso colocou em destaque, desde ao menos meados do século XVIII, uma nova forma de governar que tem a prioridade de organizar as condutas das populações e de gerenciar os riscos. Trata-se da governamentalidade como prática biopolítica:

Por "governamentalidade", eu entendo o conjunto constituído por instituições, os procedimentos, análises e reflexões, os cálculos e as táticas que permitem exercer essa forma bem específica, embora muito complexa, de poder que tem por alvo principal a população, por principal forma de saber a economia

\footnotetext{
25 Pois bem, é momento de completar a exposição que fizemos até aqui esclarecendo que por "estética" não entendemos uma disciplina ou campo da Filosofia, com seus temas e métodos próprios, mas um modo de pensamento que diz respeito ao sensível. Concordamos nisso com o ponto de vista de Jacques Rancière à respeito da filosofia de Deleuze, ao comentar: "A estética não é um saber sobre as obras, mas um modo de pensamento que se desdobra acerca delas e que as toma como testemunhos de uma questão: uma questão que se refere ao sensível e à potência de pensamento que o habita antes do pensamento, sem o conhecimento do pensamento." (RANCIÈRE, Existe uma estética deleuzeana?, 505). Outro grande expoente da filosofia contemporânea, David Lapoujade, analisando a obra de um grande filósofo, mas esquecido entre os contemporâneos, Étienne Souriau, teceu um belo comentário: "Uma das profundas originalidades de seu pensamento é que a estética deixa de representar um papel secundário ou acessório, não é mais um departamento ou uma região da filosofia, como dizemos da estética de Hegel ou de Schelling, é toda a filosofia que é suscetível de uma estética superior, dimensão que, em L'Instauration philosophique, se identifica como uma 'filosofia da filosofia'. Antes de falar de filosofia da arte, é preciso falar de uma arte da filosofia, o que nada tem de retórico: é preciso supor uma arte por meio da qual cada filosofia se coloque ou se instaure ela própria, antes de se exercer em determinado campo."
} (LAPOUJADE, As existências mínimas, 12-13). 
política, por instrumento técnico essencial os dispositivos de segurança. Em segundo lugar, por "governamentalidade" eu entendo a tendência, a linha de força que, em todo o Ocidente, não cessou de conduzir, e por muito tempo, para a preeminência desse tipo de poder que podemos chamar de "governo" sobre todos os outros - soberania, disciplina - e que trouxe, por um lado, o desenvolvimento de toda uma série de aparelhos específicos de governo [e, por outro lado], o desenvolvimento de toda uma série de saberes. Enfim, por "governamentalidade" eu creio que se deveria entender o processo, ou melhor, o resultado do processo pelo qual o Estado de justiça da Idade Média, que nos séculos XV e XVII se tornou o Estado administrativo, encontrou-se pouco a pouco "governamentalizado" 26.

Ora, a ação política não definiu os fatores de surgimento - por assim dizer, o ponto de ignição da contaminação - da pandemia de Covid-19, mas diz respeito ao tipo de resposta que é dada face ao problema para dirimi-lo; e não poderia ser senão uma resposta global, porque se trata de uma questão de saúde pública mundial, capilarizada em muitos países por condições sanitárias precárias e alimentada pela desinformação, muitas vezes proposital, de líderes políticos. Aqui podemos encontrar o ponto em que se cruzam a governamentalidade e o uso da informação estatística e, igualmente, o problema que resta apontar:

A estatística, etimologicamente, é o conhecimento do Estado, o conhecimento das forças e dos recursos que caracterizam um Estado em um dado momento. Por exemplo: conhecimento da população, medida da sua quantidade, medida da sua mortalidade, da sua natalidade, estimativa das diferentes categorias de indivíduos em um Estado e da sua riqueza, estimativa das riquezas virtuais de que um Estado dispõe: as minas, as florestas, etc., estimativa das riquezas produzidas, estimativa das riquezas que circulam, estimativa da balança comercial, medida dos efeitos de taxas e de impostos - são todos esses dados e muitos outros que vão constituir agora o conteúdo essencial do poder soberano. Não mais, portanto, corpus de leis ou habilidade em aplicá-las quando necessário, mas conjunto de conhecimentos técnicos que caracterizam a realidade do próprio Estado $^{27}$.

Qual o problema? Se, como de fato ocorre, as estatísticas mostram que os fenômenos afeitos às populações têm regularidade, taxas de incidência e exceções, - "que a população comporta efeitos próprios da sua agregação e que esses fenômenos são irredutíveis aos da família: serão as grandes epidemias, as expansões endêmicas, a espiral do trabalho e da riqueza"28 -, por que, então, ao se aumentar a quantidade de informação disponível para um tratamento estatístico aumenta-se, a contra parte, o gradiente de entropia dessas populações? Quer dizer que, apesar das técnicas e táticas biopolíticas aplicáveis com base em informação estatística segura que permita o conhecimento, a manipulação e a previsão de índices que demarcam as populações - tais como, os surtos de novas doenças -, é fato que maior quantidade de informação, inclusive estatisticamente organizada, não diminui a ocorrência de estados possíveis onde a deflagração de uma nova pandemia é bastante provável.

Supomos que esse problema ocorre, em certa medida, em razão de que vivemos em uma sociedade de controle, muito diferente daquelas dos séculos XVIII e XIX, e de parte do século XX. São notáveis a clareza e a assertividade com as quais Deleuze falou dela:

Encontramo-nos numa crise generalizada de todos os meios de confinamento, prisão, hospital, fábrica, escola, família. A família é um "interior", em crise como qualquer outro interior, escolar, profissional, etc. Os ministros

\footnotetext{
${ }^{26}$ FOUCAULT, Sécurité, territoire, population, 111-112 (tradução nossa).

${ }^{27}$ FOUCAULT, Sécurité, territoire, population, 280 (tradução nossa).

${ }^{28}$ FOUCAULT, Sécurité, territoire, population, 108 (tradução nossa).
} 
competentes não param de anunciar reformas supostamente necessárias. Reformar a escola, reformar a indústria, o hospital, o exército, a prisão; mas todos sabem que essas instituições estão condenadas, num prazo mais ou menos longo. Trata-se apenas de gerir sua agonia e ocupar as pessoas, até a instalação das novas forças que se anunciam. São as sociedades de controle que estão substituindo as sociedades disciplinares" 29 .

Qual a lógica dessas sociedades? Antes de mais nada, podemos dizer que destoam bastante das relações que definem as regularidades das populações, biopoliticamente falando.

\section{Considerações finais}

Atualmente, a política não é menos estatística do que já supomos que ela tenha sido na comparação com outras formas de conhecimento da sociedade, como a sociologia e a economia. Na verdade, o saber estatístico praticamente adentrou os campos do conhecimento sobre a vida, tornando-se indispensável para o planejamento e a tomada de decisões em termos de saúde pública, por exemplo. Calcular é a palavra de ordem para conhecer, modificar e prever situações adversas ao governo das pessoas e das instituições.

Mas, como mencionamos no início, isso não é visto sem preocupação. 0 problema da governamentalidade em uma sociedade de controle não diz respeito à organização do conjunto dos saberes e das técnicas para gerir as populações, mas, em um segundo plano, está relacionado à conversão da informação estatística em arte de governo, em discurso e em estratégia dos quais se espera que haja alguma efetividade. "A biopolítica lida com a população, e a população como problema político, como problema a um só tempo científico e político, como problema biológico e como problema de poder"30. Mas essa composição parece estar muito longe do ideal de uma sociedade administrada, uma vez que conjugar a noção de população como problema político e biológico aumenta, consideravelmente, a quantidade de informação disponível; e quanto mais informação houver no sistema, maior será a variedade de estados possíveis e de ocorrências prováveis longe do equilíbrio e, portanto, entrópicas como o são as pandemias.

0 problema consiste em que à luz da biopolítica um conjunto de elementos e de relações inerentes às sociedades de controle deixam de ser explicados. Portanto, os diferentes modos de controle que formam uma geometria variável, usualmente inscrita na linguagem numérica, são estados metaestáveis e coexistentes em uma dada modulação, como podemos depreender do argumento de Deleuze ${ }^{31}$. Já, a governamentalidade pressupõe regularidade para lidar com a população, mas o controle remete a flutuações e modulações em um processo que nunca termina, como, por exemplo, as oscilações das bolsas de valores.

Realidade distópica, realismo distópico ou já uma utopia negativa? 0 problema parece residir na curva onde a governamentalidade encontra as modulações das sociedades de controle, quando não mais consegue governá-las.

\section{Referências}

CLAEYS, G. Dystopia: a natural history. A study of modern despotism, its antecedents, and its literary diffractions. Oxford: Oxford University Press, 2017.

\footnotetext{
${ }^{29}$ DELEUZE, Conversações, 220.

${ }^{30}$ FOUCAULT, Em defesa da sociedade, p. 292-293.

${ }^{31}$ DELEUZE, Conversações, 221-222.
} 
CLAEYS, G. The origins of dystopia: Wells, Huxley and Orwell. In: Utopian literature. Cambridge: Cambridge University Press, 2010.

DARDOT, P.; LAVAL, C. A prova política da pandemia. Dossiê: Coronavírus e sociedade. Blog da Boitempo. Editorial. Disponível em: https://blogdaboitempo.com.br/dossiestematicos/dossie-coronavirus/. Acesso em: 20 de abr. 2020.

DELEUZE, G. Conversações, 1972 - 1990. São Paulo: Editora 34, 1992.

FOUCAULT, M. Dits et écrits II - 1970 - 1975. Paris: Éditions Gallimard, 1994. p. 433-434.

FOUCAULT, M. Dits et écrits III - 1976 - 1979. Paris: Éditions Gallimard, 1994. p. 429-442; 571594; 818-825.

FOUCAULT, M. Dits et écrits IV - 1980 - 1988. Paris: Éditions Gallimard, 1994. p. 562-578; 591598; 668-678; 679-688; 730-735.

FOUCAUlT, M. Em defesa da sociedade: curso dado no Collège de France (1975-1976). São Paulo: Martins Fontes, 1999.

FOUCAULT, M. Sécurité, territoire, population. Cours au Collège de France (1977-1978). Paris: Hautes Études/Gallimard/Seuil, 2004.

LAPOUJADE, D. As existências mínimas. São Paulo: n-1 edições, 2017.

RANCIÈRE, J. Existe uma estética deleuzeana? In: ALLIEZ, E (org.). Gilles Deleuze: uma vida filosófica. São Paulo: Ed. 34, 2000. p. 505-516.

WORLD HEALTH ORGANIZATION (WHO). Coronavirus disease (COVID-19) pandemic. Disponível em: https://www.who.int/home. Acesso em: 20 abr. 2020.

\section{Indicação de bibliografia publicada no Brasil}

FOUCAULT, M. Arqueologia das ciências e história dos sistemas de pensamento. 2 ed. Rio de Janeiro: Forense Universitária, 2005. p. 335-351. (Ditos e Escritos; II).

FOUCAULT, M. Arte, epistemologia, filosofia e história da medicina. Rio de Janeiro: Forense Universitária, 2001. p. 222-247; 259-270; 307-309; 425-440. (Ditos e Escritos; VII).

FOUCAULT, M. Ética, sexualidade, política. 2 ed. Rio de Janeiro: Forense Universitária, 2006. p. 225-233; 240-251; 288-293. (Ditos e Escritos; V).

FOUCAULT, M. Nascimento da biopolítica: curso dado no Collège de France (1978-1979). São Paulo: Martins Fontes, 2008.

FOUCAULT, M. Segurança, território, população: curso dado no Collège de France (1977-1978). São Paulo: Martins Fontes, 2008. 